\title{
Characterization of malaria transmission by vector populations for improved interventions during the dry season in the Kpone-on-Sea area of coastal Ghana
}

David P Tchouassi ${ }^{1,2^{*}}$, Isabella A Quakyi ${ }^{1}$, Ebenezer A Addison ${ }^{1}$, Kwabena M Bosompem², Michael D Wilson ${ }^{2}$, Maxwell A Appawu ${ }^{2}$, Charles A Brown ${ }^{2}$ and Daniel A Boakye ${ }^{2}$

\begin{abstract}
Background: Malaria is a major public health problem in Ghana. We present a site-specific entomological study of malaria vectors and transmission indices as part of an effort to develop a site for the testing of improved control strategies including possible vaccine trials.

Methods: Pyrethrum spray catches (PSC), and indoor and outdoor human landing collections of adult female anopheline mosquitoes were carried out over a six-month period (November 2005 - April 2006) at Kpone-on-Sea, a fishing village in southern Ghana. These were morphologically identified to species level and sibling species of the Anopheles gambiae complex further characterized by the polymerase chain reaction (PCR). Enzyme-linked immunosorbent assay was used to detect Plasmodium falciparum mosquito infectivity and host blood meal sources. Parity rate was examined based on dilatation of ovarian tracheoles following dissection.

Results: Of the 1233 Anopheles mosquitoes collected, An. gambiae s.l. was predominant (99.5\%), followed by An. funestus (0.4\%) and An. pharoensis (0.1\%). All An. gambiae s.l. examined (480) were identified as An. gambiae s.S. with a majority of $\mathrm{M}$ molecular form (98.2\%) and only $1.8 \% \mathrm{~S}$ form with no record of M/S hybrid. A significantly higher proportion of anophelines were observed outdoors relative to indoors $\left(x^{2}=159.34, d f=1, p<0.0000\right)$. Only An. gambiae M molecular form contributed to transmission with a high degree of anthropophily, parity rate and an estimated entomological inoculation rate (EIR) of 62.1 infective bites/person/year. The Majority of the infective bites occurred outdoors after 09.00 pm reaching peaks between 12.00-01.00 am and 03.00-04.00 am.

Conclusion: Anopheles gambiae M molecular form is responsible for maintaining the status quo of malaria in the surveyed site during the study period. The findings provide a baseline for evidence-based planning and implementation of improved malaria interventions. The plasticity observed in biting patterns especially the combined outdoor and early biting behavior of the vector may undermine the success of insecticide-based strategies using insecticide treated nets (ITN) and indoor residual spray (IRS). As such, novel or improved vector interventions should be informed by the local malaria epidemiology data as it relates to vector behavior.
\end{abstract}

Keywords: Anopheles gambiae M molecular form, Plasmodium falciparum, Malaria transmission, Biting pattern, Parity rate, EIR, Ghana

\footnotetext{
* Correspondence: dtchouassi@icipe.org

${ }^{1}$ School of Public Health, University of Ghana, Legon, Ghana

${ }^{2}$ Noguchi Memorial Institute for Medical Research, University of Ghana, Legon, Ghana
} 


\section{Background}

The burden of malaria remains high in many African countries, despite increasing effort to control the disease due to a persistent high level of transmission [1,2]. Determining the intensity of transmission by mosquito populations is a key component of epidemiologic studies of malaria. This is usually estimated using the entomological inoculation rate (EIR), an index which provides the most direct measure of the risk of human exposure to the bites of infective anopheline vectors [3]. The EIR is also highly valuable for monitoring the suitability of vector control operations [4]. The risk of human exposure to infectious bites of vectors in Africa is however, not uniform [5]. Indeed, the transmission pattern may even vary greatly from region to region and even from village to village in the same district [6-8].

In most malarious regions of the world, there is little baseline information on vector populations and variation in the intensity of malaria transmission. Consequently, currently used vector control methods via indoor residual sprays (IRS) and Insecticide treated bed nets (ITNs) are applied without regard to the local epidemiology of the disease, especially the relationship to vector behavior and intensity of transmission. Optimum effectiveness of these control strategies presumably depends on vectors biting at hours when most people are in bed [9]. However, behavioral heterogeneity of Anopheles species in ecologically different localities is widespread [10] and could dictate the success of these strategies. For example, The Garki malaria control project in Nigeria in the 1970s failed largely because of failure to recognize persistent malaria transmission by exophilic outdoorresting mosquitoes, despite widespread indoor residual insecticide spraying [11-13].

Therefore, the implementation of effective vector control strategies requires information on the main vectors, their population structure, distribution and efficiency in malaria transmission and variation even within local scales [1]. Moreover, entomological parameters to identify the main vectors for selecting suitable vector control options $[9,14,15]$ are required in several communities in Africa, including Ghana, where malaria remains endemic in several communities $[16,17]$.

Efforts are being made to achieve malaria elimination and eradication worldwide $[18,19]$. The strategies being adopted include improved vector control, chemotherapy and possible vaccination. Kpone-on-Sea, a coastal fishing village in southern Ghana, is being developed as a possible site for testing various malaria control strategies with the hope to improve case management, control and prevention of the disease. To achieve effectiveness in these strategies, all aspects of malaria epidemiology need to be well understood including a better understanding of the vec tor transmission indices. Thus, this paper describes an entomological study on the vectors of malaria and their relative contributions to Plasmodium falciparum transmission at Kpone-on-Sea. The study was conducted over a period of six months (November 2005 - April 2006) during the dry season especially where vectors are likely to be confronted with highly variable and challenging climatic conditions with likely change on the disease transmission patterns.

\section{Methods}

\section{Study area: kpone-on-Sea}

Kpone-on-Sea is a fishing village situated at $5^{\circ} 69^{\prime} \mathrm{N}, 0^{\circ} 06^{\prime} \mathrm{E}$ within the coastal savanna belt of West Africa. It is bordered on the East by Prampram, on the West by Tema, on the South by the Gulf of Guinea (Atlantic Ocean), and on the North by shrub land, beyond which is the Ghana Industrial Free Zone. It is at an altitude of $50-100 \mathrm{~m}$ above sea level and has an equatorial climate. The village is located in the Tema Municipal Health Directorate, within the Greater Accra Region of Ghana. Temperatures range from $24.4^{\circ} \mathrm{C}-27.8^{\circ} \mathrm{C}$ with a mean of $26.1^{\circ} \mathrm{C}$. Mean annual rainfall averages between 1133 and $3606 \mathrm{~mm}$ with an average relative humidity index ranging from $78 \%$ to $85 \%$. The land formation and the drainage patterns of the four sectors of the village are such that all water from the village drains into a stream that lies on the outskirts of the village. There is also a lagoon on the outskirts of the village. A recent study in the village showed a low prevalence of malaria (11\%) with a peak parasite rate of $21 \%$ in children aged $1-5$ years. Plasmodium falciparum was the major parasite detected in all positive blood slide examinations [20]. Most of the houses are constructed of cement and corrugated iron roofing. The majority of the residents (80\%) are of the Ga and GaAdangbe ethnic groups. Most of the inhabitants are fishermen and a sizeable proportion involved in vegetable farming.

\section{Field sampling of mosquitoes, morphological identification and parity determination}

Adult mosquito surveys were carried out in the village using indoor and outdoor human landing catches (HLC) from 18:00-06:00 and indoor pyrethrum spray catches (PSC) from 06:00-08:00 (WHO, 1975). Both indoor and outdoor HLCs were conducted four nights per month (once weekly), for 6 months during the dry season from November 2005 to April 2006, in two randomly selected houses, at least $40 \mathrm{~m}$ apart by two teams of four collectors each with a supervisor. The collectors worked in pairs with a personnel change at midnight, one pair working from 6:00 pm to midnight and the next from midnight until 6:00 am. At each house, a collector was posted indoors and another outdoors with a flashlight and a mouth aspirator. Collection teams were rotated 
among blocks each month to limit temporal and/or collector bias. Each month, before continuing surveys of nonsampled households, an attempt was made to inspect premises that were previously closed or where access had been refused. Access to these areas was attempted at least three times. Different pairs of houses were visited every month. Collected mosquitoes were sorted out and the female anophelines morphologically identified using taxonomic keys [21,22]. The ovaries of all fresh unfed specimens were dissected and examined for parity determination [23]. The carcasses of each dissected mosquito were preserved individually on cotton wool over a desiccant (silica gel) in labeled Eppendorf tubes and stored at $-20^{\circ} \mathrm{C}$ for immunological and molecular biological analyses.

\section{PCR identification of the Anopheles gambiae complex}

Genomic DNA of An. gambiae s.l. mosquitoes was extracted by homogenizing a mosquito leg in $50 \mu \mathrm{l}$ of sterile double distilled water in $1.5 \mathrm{ml}$ Eppendorf tube using sterile plastic pestles. The homogenates were then boiled for 10 minutes, allowed to cool and kept at $-20^{\circ} \mathrm{C}$ until required. The PCR method of Scott et al. [24] was used for the identification of the sibling species of the An. gambiae complex. A fraction of the Anopheles gambiae s.s. specimens were further analyzed to determine the $\mathrm{M}$ and $\mathrm{S}$ molecular forms as described by Favia et al. [25]. The digests were visualized in ethidium bromide stained $2 \%$ agarose gels.

\section{Determination of $P$. falciparum sporozoite infections and human blood index}

The head and thorax of each mosquito were separated from the rest of the body, homogenized in blocking buffer $(0.5 \%$ Casein, $0.1 \mathrm{~N} \mathrm{NaOH}, 1 \mathrm{x}$ PBS) and a portion of the homogenate assayed by ELISA for the presence of circumsporozoite antigens (CSA) of $P$. falciparum as described by Wirtz et al. [26]. Positive controls (Kikergaard \& Perry Laboratories, USA) and negative controls (uninfected laboratory reared mosquitoes) were assayed simultaneously. A specimen was considered positive if a visual green colour was detected with an optical density (OD) value (at $405 \mathrm{~nm}$ ) of at least the mean of the negative controls plus two standard deviations.

Blood-fed Anopheles species from house-resting collections (i.e., PSC) were tested for the source of the blood meals using alkaline phosphatase-conjugated immunoglobulin Gs (IgGs) of human, goat, and bovine (Sigma Co., St. Louis, MO, USA). The ELISA results were read visually according to the protocol of Beier et al. [27]. The human blood index (HBI) was calculated as the proportion of blood-fed mosquitoes that had fed on humans out of the total tested.

\section{Data analyses}

Entomological parameters considered were: 1) Manbiting rate, calculated as the number of bites received per person per night of collection using the formula by Lines et al. [28]; 2) Infection rate, measured as the proportion of mosquitoes found to contain circumsporozoite antigen (CSA) by ELISA; 3) Parity rate, measured as the ratio of parous mosquitoes to the total of parous and nulliparous mosquitoes dissected; 4) Entomological inoculation rate (EIR), derived as the product of the man biting rate and circumsporozoite antigen rate as determined by ELISA; 5) The human blood index (HBI), which is the proportion of mosquitoes found to contain human IgG by ELISA. Differences in the abundance of Anopheles mosquitoes (indoor and outdoor) were analyzed using the chi-square goodness-of-fit test at $\mathrm{P}=0.05$ level of significance using R statistical software [29].

\section{Ethical considerations}

Informed consent from all the participants and ethical approval from the Noguchi Memorial Institute for Medical Research Institutional Review Board (NMIMR-IRB) was obtained. A sensitization rally was organized with the population during which the purpose of the study was clearly explained. Free informed consent of volunteers (to participate in mosquito collections) and heads of families was requested through individual discussions and group meetings, prior to the enrolment of their house in the study. Presumptive malaria treatment was given throughout the course of the study to volunteers as recommended by the National Malaria Control Programme.

\section{Results}

Anopheline species abundance

A total of 1,233 Anopheles mosquitoes were collected during the study period. Of these, An. gambiae s.l. constituted $99.5 \%$, followed by An. funestus (0.4\%) and of An. pharoensis $(0.1 \%)$. Table 1 shows the species composition by the different collection methods.

\section{Species and molecular forms of Anopheles gambiae s.s}

A total of 480 (inclusive of the 15 samples that were positive for CSA) out of 1,209 morphologically determined

\section{Table 1 Total captures of Anopheles mosquitoes by collection methods at Kpone-on-Sea}

\begin{tabular}{lllll}
\hline \multirow{2}{*}{$\begin{array}{l}\text { Collection } \\
\text { method }\end{array}$} & \multicolumn{3}{c}{ Anopheles species } & Total \\
\cline { 2 - 5 } & An. gambiae s.I. & An. funestus & An. pharoensis & \\
\hline HLC (Indoor) & $383(31.68)$ & $4(80)$ & 0 & 387 \\
\hline HLC (Outdoor) & $826(68.32)$ & $1(20)$ & $1(100)$ & 828 \\
\hline PSC (Indoor) & $18(100)$ & 0 & 0 & 18 \\
\hline Total & 1227 & 5 & 1 & 1233
\end{tabular}

HLC, human landing catches; PSC, pyrethrum spray catches; Numbers in parentheses are percentages. 
An. gambiae s.l. specimens were identified further by PCR as An. gambiae s.s. Molecular forms of approximately a tenth of the identified An. gambiae s.s. (inclusive of the 15 samples positive for CSA) were further determined. The M-form constituted $98.2 \%$ while the S-form constituted 1.8\% $(n=56)$. All the samples, which showed positive for CSA of P. falciparum where of the M-molecular form An. gambiae s.s.

Figure 1 shows the monthly indoor and outdoor species composition of the anopheline mosquitoes caught throughout the study period. Except in November 2005, a higher proportion of Anopheles mosquitoes were observed outdoors than indoors during all the months throughout the study period and the overall proportion of anopheline mosquitoes caught outdoors (68.15\%) was significantly higher than those caught indoors (31.85\%) $\left(\chi^{2}=159.34, \mathrm{df}=1, \mathrm{p}<0.0000\right)$.

\section{Man-biting and parity rates}

The overall (indoor and outdoor) mean biting rates of An. gambiae s.l. was 11.37 bites/human/night (b/m/n). Only five $A n$. funestus $(0.05 \mathrm{~b} / \mathrm{m} / \mathrm{n})$ and one $A n$. pharoensis $(0.01 \mathrm{~b} / \mathrm{m} / \mathrm{n})$ were caught biting throughout the study period. The overall biting rate due to all three anopheline species for the entire period was $11.43 \mathrm{~b} / \mathrm{m} / \mathrm{n}$ (Table 2). The overall mean parity rate calculated for An. gambiae s.l. was $79.9 \%(\mathrm{n}=1209)$. Of the five $A n$. funestus sampled, four were parous, thereby recording a parous rate of $80 \%$. The only An. pharoensis captured was nulliparous. The overall parity rate for the study period was $80.25 \%(n=1215)$ (Table 3$)$.

\section{Sporozoite and entomological inoculation rates and biting patterns}

Fifteen out of the $984 A n$. gambiae s.s. examined were infected, giving a CSA rate of $1.52 \%$. None of the five An. funestus examined were positive. Only An. gambiae s.s.

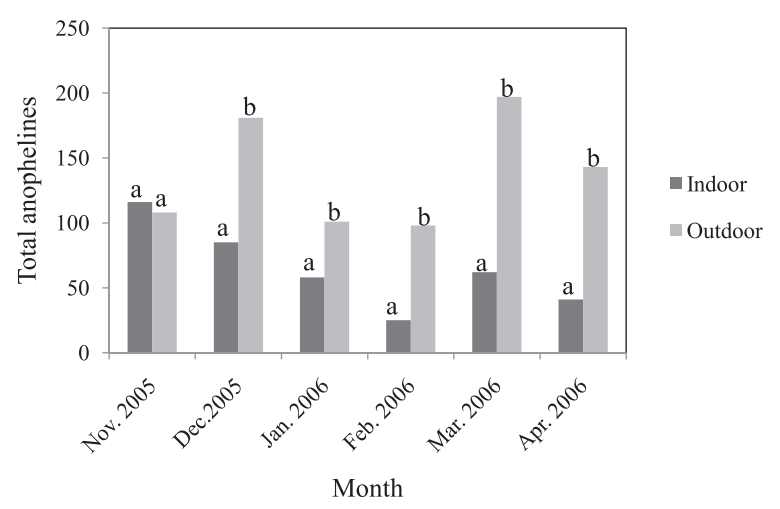

Figure 1 Monthly captures and comparisons of total anophelines by Human Landing Catches during the dry season. Bars followed by same letters are not significantly different at $p=0.05$. was found to be infective and of the molecular M-form, thus incriminating this species as the sole vector in the study site during this period. Fourteen out of the 15 infections occurred in the HLC samples, whilst one was in the PSC samples. Of the fourteen HLC infections, eleven occurred in outdoor samples and three in indoor samples. All the infective HLC mosquitoes were caught between $9.00 \mathrm{pm}$ and $5.00 \mathrm{am}$. Hourly distribution of sporozoite-positive bites of An. gambiae s.s. in the study area revealed that most of the infective bites occurred after $21.00 \mathrm{hrs}$, reaching their peak between 12.00 $01.00 \mathrm{am}$ and $03.00-04.00 \mathrm{am}$. No infective bites were recorded between 18.00 and $20.00 \mathrm{hrs}$. Of the total mosquitoes found to be infective, eight were caught in November 2005, one in December 2005, one in January 2006, two in February 2006, two in March 2006 and one in April 2006.

The estimated mean daily P. falciparum EIR or the mean number of infective bites per man per night $(\mathrm{ib} / \mathrm{m} / \mathrm{n})$ for An. gambiae s.s. was 0.17 (Table 2). Thus within a year, inhabitants in this area would have received an average of 62.1 infective bites at Kpone- on-Sea, if no precautionary measures had been taken. There were also monthly fluctuations in the EIR with the period of greatest risk to humans from infective bites of An. gambiae s.l. recorded in November 2005 and February 2006.

Biting by $A n$. gambiae commenced early in the evening and continued till daybreak (06.00-07.00 am) (Figure 2). Peak biting activity was observed between the hours of 01:00-02:00 and 02:00-03:00 both indoor and outdoor. Biting by An. gambiae s.s. was highest in December 2005 and coincided with the month in which the highest number of this species was caught probably as a result of slight showers that occurred prior to sampling during the month (Figure 1).

\section{Human blood index (HBI)}

Culex species formed the dominant species collected by the PSC accounting for $87.32 \%(\mathrm{n}=124)$ of the 142 mosquitoes collected (data not shown). Only a total of 18 blood-fed indoor resting adult An. gambiae s.s. caught were studied and the estimated HBI of this species was $66.67 \%$. Out of these, $22.22 \%(4 / 18)$ were observed to have fed on goats while none had fed on cattle. The remaining $11.11 \%$ were observed to have neither fed on humans nor goats. There were no reagents to test for other possible host blood meal sources.

\section{Discussion}

Anopheles gambiae s.s. was the dominant anopheline mosquito and the main sibling species of the An. gambiae complex in the surveyed area. This concurs with findings in coastal savanna areas of Ghana [30,31] and elsewhere in Africa [32]. Anopheles melas was absent amongst the 
Table 2 Entomological indices estimated for Anopheles mosquitoes collected at Kpone-on-Sea

\begin{tabular}{|c|c|c|c|c|c|}
\hline \multirow{2}{*}{$\begin{array}{l}\text { Anopheles } \\
\text { species }\end{array}$} & \multirow[t]{2}{*}{ No. (\%) } & \multicolumn{4}{|c|}{ Entomological indices } \\
\hline & & MBR (b/m/n) & CSA (n) & $\mathrm{HBI}(\mathrm{n})$ & $\overline{\text { EIR }}$ \\
\hline An. gambiae s.l. & $1209(99.51)$ & 11.37 & $0.015(971)$ & $67.67(18)$ & 0.17 \\
\hline An. funestus & $5(0.41)$ & 0.03 & 0 & 0 & 0 \\
\hline An. pharoensis & $1(0.08)$ & 0 & 0 & 0 & 0 \\
\hline
\end{tabular}

MBR , man biting rate; $\mathrm{b} / \mathrm{m} / \mathrm{n}$, bite/man/night; CSA, circumsporozoite antigen rate (\%); $\mathrm{HBI}$, human blood index (\%); EIR, entomological inoculation rate; (n), number examined.

human biting populations of the An. gambiae complex, although it is known to be a vector along the coast of West Africa [33-35]. This species therefore, appears not to play a role in malaria transmission in the coastal areas of Ghana. Other anophelines recorded but in reduced numbers included An. funestus and An. pharoensis, a finding which is similar to earlier work in the nearby coastal savanna area of Prampram [30].

The Anopheles gambiae s.s. M molecular form was dominant and the main malaria vector identified. The molecular M-form has been reported to have a higher vectorial capacity [36]. This fact is corroborated in our findings where a high circumsporozoite antigen rate was recorded and which was relatively higher compared to earlier studies in coastal savanna areas of Ghana [30,31]. The M-form is known to breed in permanent and semipermanent water swamps in floodable river banks favorable to its development [37]. The low occurrence of the molecular S-form in our study during the dry season is also not surprising as this form is known to be well adapted to rainfall breeding sites [38,39]. Although these molecular forms are thought to represent incipient species $[40,41]$ the factors underlining their co-existence in this area are still unclear, and deserve further investigation.

Peak indoor infective bites were also observed between the hours of $12.00-01.00$ am when most of the inhabitants were in bed; hence suggesting that if inhabitants slept under impregnated bednets, human-vector contact and thus the risk of infective bites could be reduced. However, the majority of the infective bites occurred outdoors between the hours of 12.00-01.00 am and 03.00-04.00 am which coincides with peak biting densities of this vector. An interesting finding was the distribution of sporozoite-laden bites during the night, which indicated that malaria transmission in the study site occurred in the evenings after $09.00 \mathrm{pm}$ till near daybreak
(04.00 - $05.00 \mathrm{am})$. This has important epidemiologic implications as some of the inhabitants, involved in domestic and other activities are already out of bed (by $04.00 \mathrm{am}$ ) so therefore, increases their exposure to infective inoculations.

The high degree of outdoor behavior contrasts with a greater endophilic tendency displayed by this species in earlier studies in nearby coastal area of Ghana [30]. This observation is however, not surprising as heterogeneity in biting pattern is common place even within local scales. Equally, early evening biting activity by An. gambiae s.s. was evident, a pattern which contrasts with that reported by [30] where no biting occurred during the early hours of the morning. The basis for the combined high degree of outdoor biting and early biting populations remains unclear, but could be in response to prolonged use of insecticides indoors [9]. Such characteristics would tend to reduce the impact of control strategies directed towards the indoor biting fraction of the population.

This variation in feeding behavior within vector species may have a genetic basis [11], which raises the possibility that vector control measures using insecticides could select for genotypes which are least likely to encounter the intervention. The early and outdoor biting populations may represent behavioral shifts as a consequence of phenotypic plasticity or evolutionary change within vector populations which remains unclear [42]. Regardless of the mechanism, such behavioral plasticity limits contact between vectors and insecticides, thus diminishing the effectiveness of the interventions that use them $[9,43]$. This outdoor biting activity has been linked to persistent malaria transmission in the face of mounting control measures indoors [42]. Thus there have been calls for innovative measures to develop new tools to fight malaria transmission by exploiting the

Table 3 Monthly parity rates of anopheline mosquitoes at Kpone-on-Sea

\begin{tabular}{|c|c|c|c|c|c|c|}
\hline \multirow{2}{*}{$\begin{array}{l}\text { Anopheles } \\
\text { species }\end{array}$} & \multicolumn{6}{|c|}{ Study period } \\
\hline & November 2005 & December 2005 & January 2006 & February 2006 & March 2006 & April 2006 \\
\hline An. gambiae s.l. & 91.07 (224) & $87.97(266)$ & 78.06 (155) & $62.60(123)$ & 72.37 (258) & 78.69 (183) \\
\hline An. funestus & 0 & 0 & $75(4)$ & 0 & $100(1)$ & 0 \\
\hline An. pharoensis & 0 & 0 & 0 & 0 & 0 & $0(1)$ \\
\hline
\end{tabular}

Numbers in brackets indicate numbers examined. 


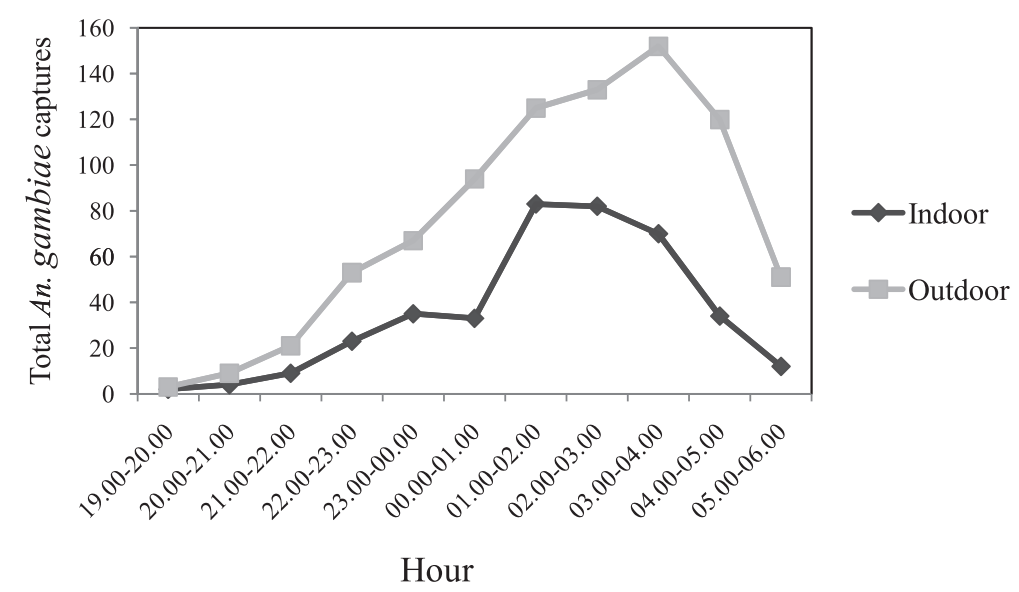

Figure 2 Hourly biting patterns of An. gambiae s.s. by Human Landing Catches during the dry season.

ecology of the vector through an integrated approach to complement current vector control strategies $[19,42,44]$.

No infected $A n$. funestus was recorded during the study period. Previous studies in other coastal areas of Ghana [30,31] have implicated this species as the second most important vector after An. gambiae s.l. Therefore, the absence of infection in An. funestus might be attributable to the low numbers caught biting; hence a longer period of survey in the rainy season is required to ascertain whether An. funestus is a significant vector at Kpone-on-Sea.

The observed parity rates for the anophelines were high. This indicates that older populations of mosquitoes tend to accumulate with time. This allows for increased feeding frequencies and thus, increased chances of the vectors becoming infected or even re-infected during subsequent feeding $[45,46]$. Our analysis showed that a higher proportion of the engorged $A n$. gambiae had fed on humans. This finding confirms the anthropophilic tendencies displayed by this species throughout most of its distribution [47], making it the most efficient malaria vector in Africa. Host blood meal detection assay was, however, conducted on only the few number of anophelines sampled using PSC. Inefficiencies of collectors could introduce bias in the number of mosquitoes that have fed on humans using human landing catches. As such, only anopheline mosquitoes collected by PSC were assayed for blood meal analyses. Few anophelines were captured using this strategy although the reason for the low captures is unclear given adequate sampling regimes that were conducted. It has been noted however, that during the dry season, as a survival strategy, adults may hide in shelters such as rodent burrows, abandoned houses and wells, thereby minimizing the chances of their detection through pyrethrum spray collections [48].

Malaria transmission dynamics have been shown to vary greatly across Africa with inoculation rates varying from as low as 0.1 to over 1000 infective bites/person/ year $(\mathrm{ib} / \mathrm{p} / \mathrm{y})$ [7,49]. Generally in Africa, when the $\mathrm{EIR}<10$, the area is considered to have unstable malaria and where EIR $>100$, malaria is said to be stable [50]. Our results therefore suggest that malaria endemicity at Kpone-on-Sea remains variable, which depends on environmental and demographic conditions such as rainfall, vegetation cover, human population density and land use patterns. The observed annual inoculation rates in Kponeon-Sea is, however, higher relative to other coastal areas of Ghana [30,31] probably due to a multiplier effect of the density and high biting rate of this species.

\section{Conclusion}

The findings provide a baseline for evidence-based planning and implementation of malaria control activities targeting vectors. An. gambiae s.s. is responsible for maintaining the status quo of malaria in the study site during the study period. The plasticity observed in biting patterns, especially the combined outdoor and early biting behavior of the vector has important consequences for the success of the widely used insecticide-based strategies using ITN and IRS. New or improved interventions should be informed by the local malaria epidemiology as it relates to vector behavior.

\section{Competing interests}

The authors declare that they have no competing interests.

\section{Authors' contributions}

DPT IAQ MDW DAB conceived and designed experiments. DPT conducted the experimental work. DPT analyzed the data. DPT IAQ EAA MDW MAA CAB $D A B$ contributed to the manuscript. All authors approved the final version of the manuscript.

\section{Acknowledgements}

We thank the residents and staff of Kpone Health Clinic for their cooperation during this project as well as the staff of the Parasitology Unit, Noguchi Memorial Institute for Medical Research (NMIMR) who contributed in diverse ways towards the completion of this work. Many thanks also to Dr. Patricia Romans (Professor Emeritus, Cell and Systems Biology), University of 
Toronto, for critical review and helpful discussions. The study was partially supported by the Deutscher Akademischer Austausch Dienst (DAAD), German Academic Exchange Service, through the African Regional Postgraduate Programme in Insect Science (ARPPIS) and the NMIMR. This investigation received financial support from the Multilateral Initiatives on Malaria (MIM) Project A30033 to Professor Isabella Quakyi (PI) through the UNICEF/UNDP/World Bank/WHO Special Programme for Research and Training in Tropical Diseases (TDR).

\section{Received: 6 August 2012 Accepted: 13 September 2012}

Published: 26 September 2012

\section{References}

1. Touré YT, Oduola AMJ, Morel CM: The Anopheles gambiae genome: next steps for malaria vector control. Trends Parasitol 2004, 20(3):142-149.

2. Griffin JT, Hollingsworth TD, Okell LC, Churcher TS, White M, Hinsley W, Bousema T, Drakeley CJ, Ferguson NM, Basáñez M-G, Ghani AC: Reducing Plasmodium falciparum malaria transmission in Africa: a model-based evaluation of intervention strategies. PLOS Med 2010, 7(8):e1000324.

3. Burkot TR, Graves PM: The value of vector-based estimates of malaria transmission. Ann Trop Med Parasitol 1995, 89:125-134

4. Coosemans M, Wery M, Mouchet J, Carnevale P: Transmission factors in malaria epidemiology and control in África. Mem Inst Oswaldo Cruz 1992, 87:385-391.

5. Smith T, Charlwood JD, Takken W, Tanner M, Spiegelhalter DJ: Mapping the densities of malaria vectors within a single village. Acta Trop 1995, $59: 1-18$

6. National Research Council: Background: malaria as a disease. In Malaria: Obstacles and Opportunities. Edited by Oaks SCJ, Mitchell VS, Pearson GW, Carpenter CCJ. Washington DC: The National Academies Press; 1991:22-36.

7. Fontenille D, Simard F: Unraveling complexities in the human malaria transmission dynamics in Africa through a comprehensive knowledge of vector populations. Comp Immunol Microbiol Dis 2004, 27:357-375.

8. Antonio-Nkonjio C, Kerah CH, Simard F, Awono-Ambene P, Chouaibou M, Tchuinkam T, Fontenille D: Complexity of malaria vectorial system in Cameroon: contribution of secondary vectors to malaria transmission. $J$ Med Entomol 2006, 43:1215-1221.

9. Pates $\mathrm{H}$, Curtis C: Mosquito behavior and vector control. Annu Rev Entomol 2005, 50:53-70.

10. Trung HD, Van Bortel W, Sochantha T, Keokenchanh K, Briet OJT, Coosemans M: Behavioral heterogeneity of Anopheles species in ecologically different localities in Southeast Asia: a challenge for vector control. Trop Med Int Health 2005, 10(3):251-262.

11. Coluzzi M, Sabatini A, Petrarca V, Di Deco MA: Behavioral divergences between mosquitoes with different inversion karyotypes in polymorphic populations of the Anopheles gambiae complex. Nature 1977, 266(5605):832-833

12. Molineaux L, Shidrawi GR, Clarke JL, Boulzaguet JR, Ashkar TS: Assessment of insecticidal impact on the malaria mosquito's vectorial capacity, from data on the man-biting rate and age-composition. Bull World Health Organ 1979, 57(2):265-274.

13. Riehle MM, Guelbeogo WM, Gneme A, Eiglmeier K, Holm I, Bischoff E, Garnier T, Snyder GM, Li X, Markianos K, Sagnon N, Vernick KD: A cryptic subgroup of Anopheles gambiae is highly susceptible to human malaria parasites. Science 2011, 331:596.

14. Banerjee A, Nayak B: Epidemiological and entomological correlation of malaria transmission in an Air Force station. MJAFI 2001, 57(3):191-193.

15. Himeidan YE, Elzaki MM, Kweka EJ, Ibrahim M, Elhassan IM: Pattern of malaria transmission along the Rahad River basin. Eastern Sudan. Parasit Vectors 2011, 4:109.

16. Adams I, Darko D, Accorsi S: Malaria: a burden explored. Bull Health Information 2004, 1(1):28-34.

17. Bell D, Wongsrichanalai C, Barnwell JW: Ensuring quality and access for malaria diagnosis: how can it be achieved? Nat Rev Microbiol 2006, 44:S7-S20.

18. Greenwood BM: Control to elimination: implications for malaria research. Trends Parasitol 2008, 24(10):449-454

19. The malERA Consultative Group on Monitoring: Evaluation, and Surveillance: A research agenda for malaria eradication: monitoring, evaluation, and surveillance. PLoS Med 2011, 8:e1000400
20. Quakyi IA, Addison AE, Bosompem K, Wilson MD, Kumar N, Boakye DA, Adjei A, Armah H, Koram KA, Quansah AG, Dodo A, Appawu MA, Mensah G, Mckakpo U, Amarh D, Lomotey F, Brown C, Ankrah I, Bruce J, Madjitey P, Adjei R, Amankwah P, Laar AK, Soyiri IN, Koranchie P, Tagoe BA: Malaria in Kpone-on-Sea: a fishing village in southern Ghana (I) Prevalence Studies, Report to WHO/TDR; 2004

21. Gillies MT, De Meillon B: The Anophelinae of Africa South of the Sahara (Ethiopian Zoogeographical region). 2nd edition. Johannesburg, South Africa: South African Institute of Medical Research; 1968.

22. Gillies MT, Coetzee M: A supplement to the Anophelinae of Africa South of the Sahara, Volume 55. Johannesburg: South African Institute for Medical Research; 1987.

23. Detinova TS: Age grouping methods in Dipterans of medical importance. In WHO Monograph Series vol. 47. Geneva: WHO; 1962:216.

24. Scott JA, Brogdou WG, Collins FH: Identification of single specimens of the Anopheles gambiae. Am J Trop Med Hyg 1993, 49:520-529.

25. Favia G, Della Torré A, Bagayoko M, Lanfrancotti A, Sagnon NF, Toure TT, Coluzzi M: Molecular identification of sympatric chromosomal forms of Anopheles gambiae and further evidence of their reproductive isolation. Insect Mol Biol 1997, 6(4):377-383.

26. Wirtz RA, Burkot TR, Graves PM, Andre RG: Field evaluation of enzyme-linked immunosorbent assays for Plasmodium falciparum and Plasmodium vivax sporozoites in mosquitoes (Diptera: Culicidae) from Papua New Guinea. J Med Entomol 1987, 24(4):233-237.

27. Beier JC, Perkins PV, Wirtz RA, Koros JK, Diggs D, Gargan TP, Koech DK: Bloodmeal identification by direct enzyme-linked immunosorbent assay (ELISA), tested on Anopheles (Diptera: Culicidae) in Kenya. J Med Entomol 1988, 25:9-16

28. Lines JD, Curtis CF, Wilkes TJ, Njunwa KJ: Monitoring human-biting mosquitoes (Diptera: Culicidae) in Tanzania with light-traps hung beside mosquito nets. B Entomol Res 1991, 81:77-84.

29. Development Core Team R: R: A language and environment for statistical computing. Vienna, Austria: R Foundation for Statistical Computing; 2010

30. Appawu MA, Baffoe-Wilmot A, Afari EA, Dunyo S, Koram KA, Nkrumah FK: Malaria vectors in two ecological zones in southern Ghana. Afr Entomol 2001, 9(1):59-65.

31. Okoye PN, Wilson MD, Boakye DA, Brown CB: Impact of the Okyereko irrigation project in Ghana on the risk of human malaria infection by Anopheles species (Diptera: Culicidae). Afr Entomol 2005, 13(2):249-253.

32. Bigoga JD, Manga L, Titanji VPK, Coetzee M, Leke RGF: Malaria vectors and transmission dynamics in coastal south-western Cameroon. Malaria J 2007, 6:5.

33. Akogbeto M: Le paludisme côtier lagunaire à Cotonou: données entomologiques, Cahiers d'études et de recherches francophones. Sante 2000, 10:267-275.

34. Diop A, Molez JF, Konate L, Fontenille D, Gaye O, Diouf M, Diagne M, Faye O: Role of Anopheles melas Theobald (1903) on malaria transmission in a mangrove swamp in Senegal. Parasite 2002, 9:239-246.

35. Awolola TS, Okwa O, Hunt TH, Ogunrinade AF, Coetzee M: Dynamics of the malaria-vector populations in coastal Lagos, south-western Nigeria. Ann Trop Med Parasitol 2002, 96:75-82.

36. ljumba JN, Lindsay SW: Impact of irrigation on malaria in Africa: paddies paradox. Med Vet Entomol 2001, 15:1-11.

37. Touré YT, Dolo G, Petrarca V, Traore SF, Bouare M, Dao A, Carnahan J, Taylor CE: Mark-release recapture experiments with Anopheles gambiae s.l. in Banambani village, Mali, to determine population size and structure. Med Vet Entomol 1994, 12(1):74-83.

38. Minakawa N, Githure Jl, Beir JC, Yan G: Anopheline mosquito survival strategies during the dry period in western Kenya. J Med Entomol 2003, 38:388-392.

39. Appawu M, Owusu-Agyei S, Dadzie S, Asoala V, Anto F, Koram K, Rogers W, Nkrumah F, Hoffman SL, Fryauff DJ: Malaria transmission dynamics at a site in northern Ghana proposed for testing malaria vaccines. Trop Med Int Health 2004, 9:164-170

40. Wondji CS, Simard F, Fontenille D: Evidence for genetic differentiation between the molecular forms $\mathrm{M}$ and $\mathrm{S}$ within the Forest chromosomal form of Anopheles gambiae in an area of sympatry. Insect Mol Biol 2002, 11:11-19.

41. Lehmann TLM, Elissa N, Maega BT, Chimumbwa JM, Watsenga FT, Wondji CS, Simard F, Hawley WA: Population structure of Anopheles gambiae in Africa. J Hered 2003, 94:133-147. 
42. Ferguson HM, Dornhaus A, Beeche A, Borgemeister C, Gottlieb M, Mulla MS, Gimnig JE, Fish D, Killeen GF: Ecology: a prerequisite for malaria elimination and eradication. PLoS Med 2010, 7(8):e1000303.

43. Govella NJ, Okumu FO, Killeen GF: Insecticide-treated nets can reduce malaria transmission by mosquitoes which feed outdoors. Am J Trop Med Hyg 2010, 82:415-419.

44. Townson H, Nathan MB, Zaim M, Guillet P, Manga L, Bos R, Kindhauser M: Exploiting the potential of vector control for disease prevention. Bull World Health Organ 2005, 83:942-947.

45. Service MW: Mosquito ecology: field sampling methods. London: Applied Science publishers; 1976.

46. Ghosh AK, Ribolla PE, Jacobs-Lorena M: The journey of the malaria parasite in the mosquito: hopes for the new century. Parasitol Today 2000, 16(5):196-201.

47. Costantini C, Sagnon N, Della Torre A, Diallo M, Brady J, Gibson G, Coluzzi M: Odor-mediated host preferences of West African mosquitoes, with particular reference to malaria vectors. Am J Trop Med Hyg 1998, 58:56-63.

48. Omer SM, Cloudsley-Thompson JL: Survival of female Anopheles gambiae Giles through a 9-month dry season in Sudan. Bull World Health Organ 1970, 42:319-330.

49. Hay SI, Rogers DJ, Toomer JF, Snow RW: Annual Plasmodium falciparum entomological inoculation rate [EIR] across Africa: literature survey, internet access and review. Trans R Soc Trop Med Hyg 2000, 94:113-127.

50. Takken $W$, Lindsay S: Factors affecting the vectorial competence of Anopheles gambiae: a question of scale. In Ecological Aspects for Application of Genetically Modified mosquitoes. Edited by Takken W, Scott TW. Wageningen: Kluwer Academic Publishers; 2003:83.

doi:10.1186/1756-3305-5-212

Cite this article as: Tchouassi et al:: Characterization of malaria transmission by vector populations for improved interventions during the dry season in the Kpone-on-Sea area of coastal Ghana. Parasites \& Vectors 2012 5:212.

\section{Submit your next manuscript to BioMed Central and take full advantage of:}

- Convenient online submission

- Thorough peer review

- No space constraints or color figure charges

- Immediate publication on acceptance

- Inclusion in PubMed, CAS, Scopus and Google Scholar

- Research which is freely available for redistribution 